\title{
AN APPLICATION OF ARTIFICIAL INTELLIGENCE ON AUDITING
}

\author{
DOI: 10.17261/Pressacademia.2019.1067 \\ PAP-V.9-2019(14)-p.65-68
}

Oktay Tas ${ }^{1}$, Haluk Mert ${ }^{2}$

${ }^{1}$ Istanbul Technical University, Department of Management Engineering, 34367, Istanbul, Turkey. oktay.tas@itu.edu.tr, ORCID: 0000-0002-7570-549X

${ }^{2}$ Istanbul Okan University, Social Sciences Institute, 34394, Istanbul, Turkey.

hamert@stu.okan.edu.tr, ORCID: 0000-0003-4596-8077

\section{To cite this document}

Tas, O., Mert, H., (2019). An application of artificial intelligence on auditing. PressAcademia Procedia (PAP), V.9, p.65-68

Permemant link to this document: http://doi.org/10.17261/Pressacademia.2019.1067

Copyright: Published by PressAcademia and limited licenced re-use rights only.

\begin{abstract}
Purpose- The purpose of this study is to examine the effects of technological developments in artificial intelligence on auditing. In this study, artificial intelligence examples used in independent auditing and the contribution of artificial intelligence to the audit sector were examined. Methodology- With the technological developments affecting the independent auditing sector, it has been observed that the efficiency of artificial intelligence has increased and the field of application of artificial intelligence has varied.

In this study, artificial intelligence applications and the artificial intelligence projects to be implemented to the auditing sector in the future were analyzed and evaluated.

Findings- According to the findings; In order to adapt artificial intelligence to businesses, it is revealed that entities need to develop their ERP systems and that there are potential difficulties for the design of artificial intelligence for each company to be audited.

Conclusion- In this study, it is thought that auditing with artificial intelligence can be performed full time and will be more effective. However, in order to spread artificial intelligence and increase productivity, it is thought that business executives should follow the developments in the world and implement them by combining them with their corporate culture. In addition, it is seen that entities need to develop ERP softwares and increase the use of digitalization and integrated programs.
\end{abstract}

Keywords: Independent auditing, artificial intelligence, machine learning

JEL Codes: G17, M42, M49

\section{DENETIMDE YAPAY ZEKA UYGULAMASI}

\section{ÖZET}

Amaç- Yapay zekada yaşanan teknolojik gelişmelerin bağımsız denetime olan etkilerini incelemek çalışmanın öncelikli amacıdır. Çalışmada, denetimde kullanılan yapay zeka örnekleri ve yapay zekanın denetim sektörüne yapacağı katkılar incelenmiştir.

Yöntem- Bağımsız denetim sektörüne etki eden teknolojik gelişmelerin yaşanmasıyla yapay zekadan alınan verimin arttığı ve yapay zekanın uygulama alanının çeşitlendiği görülmüştür.

Bu çalışmada, bağımsız denetimde var olan yapay zeka uygulamaları ve gelecekte uygulamaya konulacak yapay zeka projeleri analiz edilmiş ve değerlendirilmiştir. Bu çalışmada, teknolojik altyapının güçlenmesiyle ve farkındalığın artmasıyla ortaya çıkan yapay zekanın denetimde var olan uygulamaları ve gelecekte uygulamaya konulacak yapay zeka projeleri analiz edilerek değerlendirilmiştir.

Bulgular- Elde edilen bulgulara göre; Yapay zekanın işletmelere uyarlanabilmesi için işletmelerin ERP sistemlerini geliştirmesi gerektiği ve bağımsız denetim yapılacak her firma için, yapay zekanın tasarlanmasının olası zorlukları olduğu ortaya çıkmıştır.

Sonuç- Çalışmada, yapay zeka ile yapılan denetimin tam zamanlı yapılabileceği ve daha efektif olacağı düşünülmektedir. Fakat yapay zekanın yaygınlaşması ve verimliliğin arttırılması için işletme yöneticilerinin Dünya'da yaşanan gelişmeleri takip edip kendi kurum kültürleri ile birleştirerek uygulamaya koyması gerektiği düşünülmektedir. Ayrıca, işletmeler ERP yazılımlarını geliştirmesi gerektiği, dijitalleşme ve entegre program kullanımını arttırması gerektiği görülmüştür

Anahtar Kelimeler: Bağımsız denetim, yapay zeka, makine öğrenimi JEL Codes: G17, M42, M49 


\section{Giriş}

21. Yüzyılda yaşanan teknolojik gelişmeler, insanlar için geçmişte "hayal gücü" olarak adlandırılan hedeflere ulaştırmada büyük rol oynamıştır. Yaşanan teknolojik gelişmeler insanoğlunun ihtiyaçlarını ne kadar karşılıyor olsa da, dijitalleşme ve büyük veri oluşumu, gerçekleşen veri hareketlerinin doğruluğunu onaylamayı ve kontrolleri güçleştirmiştir. Büyük veri trafiğini kontrol etmek ve bu hareketlerdeki kontrol noktalarını güçlendirmek adına sisteme yeni bir oyuncu dahil olmuş ve gelişerek yaygınlaşmaktadır... Yapay zeka.

Yapay zeka insanoğlunun günlük hayatına girmiş ve adaptasyon sürecini başarılı ve bir o kadar hızlı bir şekilde geçirmektedir. Yapay zeka günlük hayatımızın içine girmekten öte birçok sektörü etkilemiş ve birçok sektöre yön vermiştir. Yapay zekanın etkilediği ve gelişimi konusunda katkılar sunduğu sektörlerden birisi de denetim sektörüdür.

Bu çalışmanın amacı; Yapay zekanın denetim çalışmalarını nasıl daha verimli kıldığını, koyduğu önleyici ve saptayıcı (Olayın gerçekleşmesinden çok kısa bir zamanda) kontroller ile hata ve hilenin önlenmesindeki katkılarını göstermektir.

\subsection{Yapay Zeka}

Yapay zekayı genel olarak; Hedeflenen sorunların çözümü için insan eliyle, teknolojinin sunduğu imkanlar derecesinde güçlendirilmiş, kendini geliştiren, geliştirirken öğrenen, öğrendikçe hızlanan yeni ev arkadaşımız, ofis arkadaşımız ve kişisel asistanımız olarak tanımlayabiliriz.

Günümüz anlamında yapay zeka, 20.yüzyıl'da Alan Turing'in çalışmaları ile başlamıştır. Alan Turing'in 1950'de felsefe dergisi Mind'da yer alan "Hesaplama Makineleri ve Zeka" makalesi yayımlanıştır. (Hodges, 1995) Bu makalede (Turing, 1950); Karşında bulunan kişiyi görmeden onu önceden tanımadan sorular sorarak onun bir makine ya da insan olup olmadığının nasıl anlaşılabileceğinden bahsedilmiştir. Bu makale ile bir makinenin insana yakın bir düşünme yeteneği, bilgi kapasitesi olabileceğinden bahsedilerek ufuk açıcı bir çalışma ortaya konulmuştur.

2000'li yıllara gelindiğinde yaşanan teknolojik gelişmeler ve teknolojik girdi maliyetlerinin düşüşü ile yapay zeka uygulamaları çok hızlı gelişmiştir. Yaşanan en büyük teknolojik gelişmeler; Ses tanıma, veri işleme hızındaki artış, bulut depolama ve veri işleme, makine öğrenimi ve görüntü tarama teknolojilerinin gelişimidir.

\subsection{Denetimde Yapay Zeka Kullanım Gerekliliği}

Yaşanan teknolojik gelişmeler ile bizler gündelik hayatımızı en optimum düzeyde kolaylaştırmaya çalışmaktayız. İşletmelerde, otomasyondan ve dijitalleşmeden faydalanarak çalışan işgücü büyük oranda azaltılarak veri depolama ve işleme işleri bilgisayarlar aracılığıyla yapılmaktadır.

Bilgisayar ortamında veri işleme bilgi kullanıcısına bilgiyi çeşitlendirebilme gibi büyük bir imkan vermiştir. Bu durumda veri trafiği daha çeşitlenmiş ve yoğunlaşmıştır. Oluşan bu büyük verinin denetimi eskiye oranla daha zorlaşmaktadır. Bu noktada denetçi eskiye oranla daha çok analitik denetim yöntemlerine odaklanmaktadır.

Denetçi olarak, yaşanan dijitalleşme ve otomasyon sürecine başka bir açıdan bakarsak bu durum bir denetçi için büyük bir avantaja dönüştürülebilir. Oluşan kayıtlar ve dokümanlar dijital ortamda olduğu için ve algoritmalar sistem üzerinde olduğu için yapay zekadan destek alınarak güvence seviyesi yükseltilmiş bir denetim yapılabilir.

Bilişsel teknolojilerin denetçilere olan ihtiyacı azaltacağı ya da muhtemelen ortadan kaldırabileceği düşünülebilir. Bilişsel teknolojilerin, stok sayımı veya iletişim taslağı hazırlama gibi onlarca yıldır elle gerçekleştirilen görevlerin otomasyonunu sağladığı doğrudur. Buna karşın, bu durum denetçiye alışkanlık ile odaklanılan alanlara odaklanma yerine riskli alanlara odaklanma üzerine daha fazla imkan verecektir. Bununla birlikte, bilişsel teknolojilerin potansiyeli sadece rutin görevleri otomatikleştirmekle kalmaz, aynı zamanda ilk sonuçlarla karşılaştırılabilecek düşünce süreçlerini modelleyerek denetçinin mesleki yargısını da artırabilir. (Davenport, Raphael, 2017)

\subsection{Denetimde Yapay Zeka Kullanım Alanları}

Denetim çalışmalarında yapay zekanın kullanımı hızla artmaktadır. Günümüzde 4 büyük denetim şirketi (EY, Deloitte KPMG, PWC) başta olmak üzere, yapay zeka uygulamaları denetim çalışmalarını kolaylaştırmak üzere dizayn edilmektedir. Deloitte'un Argus (Deloitte, 2018) adlı yapay zeka uygulaması ile işletmelerin bankalar ile düzenlediği kredi sözleşmeleri, denetlenen firmaların müşterileri ile imzaladığı satış sözleşmeleri, alım yaptığı firmalar ile imzaladığı alım sözleşmeleri taranmaktadır. Bu tarama sonucu oluşan bilgiler, denetçinin programa girdiği anahtar veriler ile analiz edilmektedir ve çalışma sonucunda program uygulama tarafından denetçiye raporlanmaktadır. EY, bulut temelli bilgi işleme tekniklerini ve nesnelerin internetini kullanarak stok sayımlarında dronelardan destek alınması üzerine çalışmalar yürütmektedir (EY, 2017). Bu çalışmalar ile stokların durumu anlık olarak denetim ekibince takip edilebilecek, daha doğru, daha hızlı ve daha fazla noktadan doğrulama alınarak güvence seviyesi yükseltilebilecektir. KPMG clara (KPMG,2017) ile tam zamanlı denetim yapılmasında çalışmalar yürütmektedir. Clara ile denetlenen işletmelerin finansal durumlarını etkileyebilecek her türlü veri (Muhasebe kayıtları, ticari sözleşmeler, kredi sözleşmeleri, mailleşmeler, konferans konuşmaları, vb.) incelenmektedir. Şüpheli/beklenmeyen bir durum ile karşılaşılması halinde denetçiler bilgilendirilmektedir. PWC ise denetim alanında GL.ai ile yapay zeka uygulamalarını hayata geçirmiştir (PWC, 2019). Bu uygulama ile işletmenin muhasebe kayıtları anlık olarak incelenmekte ve inceleme sonucunda anlık raporlama yapılarak denetim ekibi bilgilendirilmektedir.

\section{LITERATÜR INCELEMESI}

Yapay zeka uygulamaları, özellikle $2000^{\prime} l i$ yıllardan günümüze gelen hızlı teknolojik gelişmeler ile gelişmiş ve etkilerinin görülmesiyle kullanımı yaygınık kazanmıştır. İncelenen kaynaklarda yapılan uygulamalar ve uygulama düşünceleri üzerine yapılan literatür inceleme sonuçlarına aşağıda yer verilmiştir. 
Serçemeli (2018), makalesinde teknolojik gelişimin çalışanların iş süreçlerini kolaylaştırdığından, fakat bu durumun istihdamda azalışa neden olacağından bahsetmiştir. Çalışmada teknolojik gelişmelerin, iş sürçlerine ve departmanlara (Tahsilat/Ödeme, tedarik, denetim, dönem kapanış prosedürleri) olan etkilerinden bahsedilmiştir. Bunlara ek olarak yapay zekanın iş dünyasına, muhasebe ve denetim alanlarına yapması beklenen olası etkilerden bahsedilmiştir. Yapay zeka ve dijitalleşme süreçlerinin uygulamaya aktarılmasında karşıaşılan zorluklara değinilmiştir.

Luo, Meng ve Cai (2018), günümüzde tarım, ticaret, eğitim ve hizmet sektörü gibi birçok kişinin hayatına etkisi olan alanlarda yapay zekadan faydalanıldığını belirtmiş̧ir ilgili çalışmada. İşletme çalışanlarının tecrübelerindeki yetersizlik, yüksek bütçeli yatırımlardan uzun vadede pozitif etki elde etme, sektörde profesyonel kişilerin yetkinliklerinin eksikliklerinin, okullardaki eğitim içeriklerinin bu alana yönelik bilgi eksikliklerinin olması bu çalışmalarının yaygınlaştııımasını negatif yönde etkilediğinden bahsedilmiştir. Bunun yanında, devletlerin muhasebe alanında yapay zeka uygulamalarının yaygınlaştııı ması için bu çalışmaları desteklemesi, işletme yönetimlerinin yapay zeka teknoloji uygulamalarını desteklemesi, okullarda muhasebe öğretimindeki kalitenin arttırılması, muhasebecilerin öğrenimlerini hayat boyu planlama ile yapılmasının muhasebe alanında yapay zeka uygulamalarını arttıracağı belirtilmiştir.

ICAEW'in (2018) makalesinde yapay zeka uygulamalarının gelecekte muhasebecilik mesleğine nasıl yön vereceği vurgulanmıştır. Geleceğin bugünden şekillendiğine, bu yüzden gelişmeleri takip etmenin önemli olduğuna dikkat çekilmiştir. Var olan sistemi savunmak yerine radikal kararlar alarak yeniliklerin uygulamaya aktarılması gerektiği söylenmiştir. Teknolojik gelişmelere dayalı makine öğrenimi hızı ve etki alanının artmasının güzel yansımalarının olmasıyla birlikte makinelerin uygulama alanlarının sınırlı olduğuna değinilmiş ve bu noktada insanların makinelerle nasıl çalışma yapabileceklerine değinilmiştir.

Issa, Sun, ve Vasarhelyi'nin, (2016) makalelerinde yapay zekayı oluşturan, geliştiren ve yaygınlaştıran temel teknolojik gelişmelere (Tarama ve optik karakter tanıma, elektronik kayıt, bulut sistemleri, blockchain ve veri depolama) değinilmiştir. Derin bilgisayar öğrenmesinin çeşitli işlevleri denetçilere; Kaynak belgeleri inceleme (örneğin, banka çeki, mevduat fişi, satış faturası), işleme, konferans görüşmelerini analiz etme, e-postaları analiz etme, basın bültenleri, haberler ve bunlardan aranılan verileri çıkarma, geleneksel finansal özellikleri desteklemek için kullanılan ilave destekleyici kanıtlar toplama gibi alanlarda çalışma yapılabilmesi yolunda yeni imkanlar tanıdığı söylenmiştir. Dijitalleşme ile işletmelerin bilgisayarların incelemesine sunabileceği büyük bir veri yığını oluştuğu söylenmiş ve yapay zeka ile denetimin bu sayede kolaylaştı̆̆ı söylenmiştir. Bu dijital veri oluşum sürecinde yapay zeka ile işletmelerde sürekli denetimin yapılabileceği belirtilmiştir. Çalışmada denetim çalışmalarına (Ön planlama süreci, Sözleşme süreci, iç kontrolleri anlama ve risk faktörlerini belirleme süreci, kontrol risklerinin değerlendirilme süreci, maddi doğrulama testleri, denetim kanıtlarının değerlendirilmesi, denetim raporu) yapay zekanın nasıl katkı sağlayacağı ve bu süreçlerin yapay zeka ile nasıl dönüşüme sokularak daha efektif hale getirileceği anlatılmışır.

Yapay zeka birçok sektörde işgücüne olan ihtiyacı azaltmıştır. Greenman, (2017) çalışmasında yapay zekanın muhasebe ve denetim sektöründe yaratması muhtemel işgücü intiyacına olan azalışa değinmiştir.

Wehle, (2019). Çalışmasında yapay zekanın getirdiği fırsatlar (Hızlı karar verme, daha iyi geleceği tahmin etme, verimlilikte artış, insan çalışmalarına dayalı hataların eliminasyonu, insanların performanslarının iyileştirmede yardım, maliyetlerde ve iş gücünde azalış) ve yapay zekanın karşılaştığı zorluklardan (kültürel karşı durma, emek yoğun çalışılan yerlerde işsizlik tehdidi, empati ve ahlaki değerlerdeki eksiklikler ve teknolojik gelişmelerin hızlanması) bahsetmiştir.

\section{BULGULAR VE TARTIŞMA}

Çalışma kapsamında yapılan literatür incelemesi sonucunda, yapay zekanın denetim alanında kullanımının yaygınlaşmasını kıııtlayan bazı engeller olduğu görülmüştür. Bu engellerin başında işletmelerin çeşitli muhasebe programları kullanıyor olması ve entegre program kullanmıyor olması gelmektedir. Bunun yanında kullanılan veriler işletmeler arasında farklılık göstermektedir.

İşletmelerin farkı muhasebe programları kullanıyor olması (Dış denetçiler için) her firma için program dilinde güncelleme yapılması gerekmektedir. Buna ek olarak denetlenen firmalarda yetkin bilgi işlem personelinin bulunmaması veya bu personellerin işletmelere uzaktan destek veriyor olması süreci yavaşlatan diğer bir etmendir. Entegre programların olmaması, yani muhasebe kayıtlarının manuel veya başka programlar ile hazırlanıyor olması yapay zekanın kontrol alanını sınırlamaktadır.

İşletmelerin faaliyet konuları, üretim veya hizmet sektöründe yer alması gibi ana farklılıklarının dışında işletme içerisinde girilen verilerde işletme özelinde farklılıklar bulunmaktadır. Bir işletme muhasebe kayıtları düzenlerken boşluk yerine nokta kullanırken diğeri boşluk veya diğer başka bir karakter kullanmaktadır. İşletmeler kendilerinin anlayacağı şekilde kısaltmalar vererek kayıt açıklaması girebilmektedir. Bu gibi farklııklar yapay zekanın veriyi anlamlandırmasını yavaşlatmakta, bazı noktalarda veriyi anlamlandırmasına engel olmaktadır.

Günümüzde, dünya çapında büyük bağımsız denetim firmalarının yapay zeka uygulamalarına öncü olduğu görülmüştür. Bu firmaların bu alanda yatıım yapması, her geçen gün yeni yapay zeka çalışmalarını kamuoyuna duyurması, yapay zekanın denetim alanında yaygınlaşacağının en büyük göstergesidir.

\section{SONUÇ}

Bu çalışmada yapay zekanın denetim sektörüne olan etkilerinin incelenmesinin başlıca nedeni, Dünya'da yaşanan ve büyük bir hızla meyvelerini veren denetim sektöründe yapay zeka uygulamaları üzerine farkındalık kazanılmasını sağlamaktır. Yapay zekanın işletme içerisinde uygulamaya konulması, yaygınlaştırı ması ve verimliliğinin artııılması yalnızca muhasebe, denetim ve finans departman çalışanları ile gerçekleşemez. İşletmenin bütün birimleri bu çalışmaları takip etmeli ve birim yöneticileri gelişim yönünde atılan adımların kendi birim çalışanlarınca uygulanmasını sağlamalıdır.

21.yüzyılda yaşanan gelişmeler diğer dönemlerden farklıdır. Gelişmeler bu yüzyılda üstel olarak gerçekleşmektedir. Tarlaları sürmek için kullanılan ve yaklaşık $5.000 \mathrm{yıl} \mathrm{önce} \mathrm{bulunan} \mathrm{saban} \mathrm{ile} \mathrm{insanoğlu} \mathrm{uzun} \mathrm{bir} \mathrm{süre} \mathrm{idare} \mathrm{etmiştir.} \mathrm{Fakat} \mathrm{günümüzde} \mathrm{bilginin} \mathrm{kolay} \mathrm{erişimi,} \mathrm{sermaye}$ edinme seçeneklerinin bolluğu ve mühendisliğin geldiği nokta ile neredeyse her gün endüstriyel tarımın gelişimine katkı sağlayacak bir 
yenilikle uyanıyoruz güne. Kurumsal işletme yöneticileri de bu hızı değişimin farkındalar. Protiviti'nin 2019 yılında yaptığı kurumsal risk araştırmasında yöneticiler ilk 10 risk içerisinde; 5. Sırada operasyonlarda değişime olan dirençi görürken 6.sırada Yıkıcı yeniliklerin ve yeni teknolojilerin hızlı gelişimi görülmektedir (Protiviti, 2019).

Yapay zeka teknolojik gelişmelerle (Bulut sistemi ile depolama ve veri işleme, data işleme hızındaki artış, ses tanıma, görüntü tanıma, tarama ve optik karakter tanıma, makine öğrenimi, nesnelerin interneti) son 10 yılda hızlı bir ilerleme kaydetmiştir. Bu gelişmeler yapay zekanın gelişiminde her ne kadar büyük ivme yaratsa da önümüzdeki yıllarda bu gelişmelerin maliyetlerindeki düşüş ve toplumun bunu iş süreçlerine adapte edip yaygınlaştırması sonucunda oluşan yeni pazarla çok büyük yenilikler ile karşılaşacağız.

Yapay zeka 21.yüzyılda birçok sektöre yön vermektedir. Denetimde bu sektörlerden biridir. Denetimde müşteri kabulünden başlamak üzere denetim raporunun imzalanmasına kadar olan bütün aşamalarda yapay zeka her bir süreçte yer almaktadır. Bağımsız denetim firmaları ve işletme iç denetim birimleri yaşanan bu büyük yeniliğe kayıtsız kalmamalı ve iş süreçlerini güncellemeli, kalifiye personel teminini yerine getirmelidir.

Denetim çalışmalarında yapay zekadan destek alınmasında saptanan engelleri, işletme yöneticileri bir araya gelip ortak çalışmalar yaparak elimine etmelidir. İşletme yöneticileri bu uygulamaların hızlı bir şekilde hayata geçirilmesi için işletme içi farkındalık çalışmaları yapmalı ve yaşanan süreci takip etmelidir.

Yapay zekanın iş birimlerine aktarımı ile denetçilerin daha çok analitik çözüm üretebilen, örüntüler arası bağ kurabilen, sektörde ve mevzuatta yaşanan yenilikleri daha hızlı öğrenen kişiler olması beklenmektedir.

Hem iç denetimde hem bağımsız denetimde yapay zeka uygulamalarının öne çıkması kaçınılmaz bir gerçektir. Yapay zeka uygulamaları ile zaman, insan kaynağı, maliyet ve etkinlik açııından önemli faydalar sağlanacağı kesindir.

\section{KAYNAKLAR}

Davenport, T., Raphael, J. (2017). 10 Rule; “Creating a Cognitive Audit,”. http://ww2.cfo.com/auditing/2017/07/creating-cognitiveaudit/

Deloitte. (2018). 16 Artificial Intelligence Projects from Deloitte Practical Cases of Applied Al. https://www2.deloitte.com/content/dam/Deloitte/nl/Documents/innovatie/deloitte-nl-innovatie-artificial-intelligence-16-practicalcases.pdf

EY. (2017). EY Scaling the Use of Drones in the Audit Process. https://www.ey.com/gl/en/newsroom/news-releases/news-ey-scaling-theuse-of-drones-in-the-audit-process

Hodges, A. (1995). Alan Turing - A Short Biography. https://www.turing.org.uk/publications/dnb.html

Greenman, C. (2017). Exploring the Impact of Artificial Intelligence on the Accounting Profession. Journal of Research in Business, Economics and Management, 8(3), 1451-1454.

ICAEW, (2018). Artificial intelligence and the future of accountancy. ICAEW's IT Faculty, 1-12. https://www.icaew.com//media/corporate/files/technical/information-technology/technology/artificial-intelligence-report.ashx?la=en

Issa, H. Sun, T. Vasarhelyi, M. A. (2016). Research Ideas for Artificial Intelligence in Auditing: The Formalization of Audit and Workforce Supplementation. Journal of Emerging Technologies in Accounting, 13(2), 1-20.

KPMG. (2017). KPMG Clara a smart audit platform. https://assets.kpmg/content/dam/kpmg/xx/pdf/2017/05/kpmg-clara-a-smart-auditplatform.pdf

Luo, J. Meng, Q. Cai, Y. (2018). Analysis of the Impact of Artificial Intelligence Application on the Development of Accounting Industry. Open Journal of Business and Management, 6, 850-856. DOI: 10.4236/ojbm.2018.64063.

Protiviti. (2019). Executive Perspectives on Top Risks 2019. https://www.protiviti.com/sites/default/files/united_states/insights/nc-stateprotiviti-survey-top-risks-2019.pdf

PWC. (2019). Audit Explorer. https://www.pwc.com/gx/en/audit-services/assets/pdf/audit-explorer-at-a-glance-on-screen.pdf

Serçemeli, M. (2018). Artificial Intelligence in Digital Transformation of Accounting and Auditing Professions. Turkish Studies, 13(30), 369386.

Turing, A. M. (1950). Computing Machinery and Intelligence. Mind, 433-560.

Wehle, H. D. (2019). Artificial Intelligence, https://www.researchgate.net/publication/330683449 Artificial Intelligence 